\title{
Development of the Healthy Eating Food Index (HEFI)-2019 measuring adherence to Canada's Food Guide 2019 recommendations on healthy food choices ${ }^{1}$
}

\author{
Didier Brassard, Lisa-Anne Elvidge Munene, Sylvie St-Pierre, Patricia M. Guenther, Sharon I. Kirkpatrick, \\ Joyce Slater, Simone Lemieux, Mahsa Jessri, Jess Haines, Rachel Prowse, Dana Lee Olstad, \\ Didier Garriguet, Jennifer Vena, Hassan Vatanpatast, Mary R. L’Abbe, and Benoît Lamarche
}

\begin{abstract}
The release of Canada's Food Guide (CFG) in 2019 by Health Canada prompted the development of indices to measure adherence to these updated dietary recommendations for Canadians. This study describes the development and scoring standards of the Healthy Eating Food Index (HEFI-2019), which is intended to measure alignment of eating patterns with CFG-2019 recommendations on food choices among Canadians aged 2 years and older. Alignment with the intent of each key recommendation in the CFG-2019 was the primary principle guiding the development of the HEFI-2019. Additional considerations included previously published indices, data on Canadians' dietary intakes from the 2015 Canadian Community Health Survey-Nutrition, and expert judgement. The HEFI-2019 includes 10 components: Vegetables and fruits (20 points), Whole-grain foods (5 points), Grain foods ratio (5 points), Protein foods (5 points), Plant-based protein foods (5 points), Beverages (10 points), Fatty acids ratio (5 points), Saturated fats (5 points), Free sugars (10 points), and Sodium (10 points). All components are expressed as ratios (e.g., proportions of total foods, total beverages, or total energy). The HEFI-2019 score has a maximum of 80 points. Potential uses of the HEFI-2019 include research as well as monitoring and surveillance of food choices in population-based surveys.
\end{abstract}

Novelty:

- The Healthy Eating Food Index-2019 was developed to measure adherence to the 2019 Canada's Food Guide recommendations on healthy food choices.

- The HEFI-2019 includes 10 components, of which 5 are based on foods, 1 on beverages and 4 on nutrients, for a total of 80 points.

Key words: Canada's Food Guide, Canadian Community Health Survey, nutrition survey, 24-hour dietary recalls, diet quality, Healthy Eating Food Index, HEFI-2019, food choices, adherence, dietary guidelines.

Résumé : La publication du Guide alimentaire canadien (GAC) en 2019 par Santé Canada a incité le développement d'indices pour mesurer le respect de ces recommandations alimentaires mises à jour pour les Canadiens. Cette étude décrit l'élaboration et les normes de notation de l'Indice de saine alimentation ("HEFI-2019 ") qui vise à mesurer l'alignement des habitudes alimentaires avec les recommandations du GAC-2019 sur les choix alimentaires des Canadiens âgés de 2 ans et plus. L'alignement sur l'intention de chaque recommandation clé du GAC-2019 était le principe fondamental qui a guidé l'élaboration du HEFI-2019. D’autres considérations comprenaient des indices publiés antérieurement, des données sur les apports alimentaires des Canadiens

Received 4 June 2021. Accepted 6 January 2022.

D. Brassard, S. Lemieux, and B. Lamarche. Centre Nutrition, santé et société (NUTRISS), Institut sur la nutrition et les aliments fonctionnels (INAF), Université Laval, Québec City, QC G1V 0A6, Canada.

L.-A. Elvidge Munene and S. St-Pierre. Office of Nutrition Policy and Promotion, Health Canada, Ottawa, ON K1A 0K9 Canada.

P.M. Guenther. Department of Nutrition and Integrative Physiology, University of Utah, Salt Lake City, UT 84112, USA.

S.I. Kirkpatrick. School of Public Health Sciences, University of Waterloo, Waterloo, ON N2L 3G1, Canada.

J. Slater. Department of Food and Human Nutritional Sciences, University of Manitoba, Winnipeg, MB R3T 2N2, Canada.

M. Jessri. Human Nutrition and Dietetics, Food, Nutrition and Health Program, The University of British Columbia, Vancouver, BC V6T 1Z4, Canada.

J. Haines. Department of Family Relations and Applied Nutrition, University of Guelph, Guelph, ON N1G 2W1, Canada.

R. Prowse. Division of Community Health and Humanities, Faculty of Medicine, Memorial University of Newfoundland, St. John's, NL A1B 3V6, Canada.

D.L. Olstad. Department of Community Health Sciences, Cumming School of Medicine, University of Calgary, Calgary, AB T2N 4Z6 Canada.

D. Garriguet. Health Analysis Division, Statistics Canada, Ottawa, ON K1A 0T6, Canada.

J. Vena. Department of Community Health Sciences, Cumming School of Medicine, University of Calgary, Calgary, AB T2N 4Z6 Canada; Alberta's

Tomorrow Project, Cancer Research \& Analytics, Cancer Care Alberta, Alberta Health Services, Calgary, AB T2T 5C7, Canada.

H. Vatanpatast. College of Pharmacy and Nutrition, School of Public Health, University of Saskatchewan, Saskatoon, SK S7V 2Z4, Canada.

M.R. L'Abbe. Department of Nutritional Sciences, Temerty Faculty of Medicine, University of Toronto, Toronto, ON M5S 1A8, Canada; WHO Collaborating Centre on Nutrition Policy for Chronic Disease Prevention, Department of Nutritional Sciences (DNS), University of Toronto, Toronto, ON M5S 3E2, Canada.

Corresponding author: Benoît Lamarche (email: benoit.lamarche@fsaa.ulaval.ca).

${ }^{1}$ This paper is 1 of 2 companion papers published in this issue of APNM (Brassard et al. 2022. Appl. Nutr. Phyiol. Nutr. Metab. This issue. doi:dx.doi.org/10.1139/ apnm-2021-0416).

(ㄱ) 2022 Brassard, Guenther, Kirkpatrick, Slater, Lemieux, Jessri, Haines, Prowse, Olstad, Vena, Vatanparast, L’Abbé, and Lamarche, and @ Her Majesty the Queen in right of Canada (2022) @ Sa majesté la Reine du chef du Canada (2022). This work is licensed under a Creative Commons Attribution 4.0 International License (CC BY 4.0), which permits unrestricted use, distribution, and reproduction in any medium, provided the original author(s) and source are credited. 
tirées de l'Enquête sur la santé dans les collectivités canadiennes de 2015-Nutrition et des jugements d'experts. Le HEFI-2019 comprend 10 composantes : Légumes et fruits (20 points), Aliments à grains entiers (5 points), Ratio d'aliments céréaliers (5 points), Aliments protéinés (5 points), Aliments protéinés d'origine végétale (5 points), Boissons (10 points), Ratio d'acides gras (5 points), Gras saturées (5 points), Sucres libres (10 points) et Sodium (10 points). Toutes les composantes sont exprimées sous forme de ratios (par exemple, les proportions d'aliments totaux, de boissons totales ou d'énergie totale). Le score HEFI-2019 présente un maximum de 80 points. Les utilisations potentielles du HEFI-2019 comprennent la recherche ainsi que le suivi et la surveillance des choix alimentaires dans les enquêtes basées sur la population. [Traduit par la Rédaction]

\section{Les nouveautés :}

- L'Indice de saine alimentation-2019 a été développé pour mesurer le respect des recommandations du Guide alimentaire canadien 2019 sur les choix alimentaires sains.

- L'HEFI-2019 comprend 10 composantes dont cinq à base d'aliments, une à base de boissons et quatre à base de nutriments pour un total de 80 points.

Mots-clés : guide alimentaire canadien, Enquête sur la santé dans les collectivités canadiennes, enquête sur la nutrition, rappels alimentaires de 24 heures, qualité de l'alimentation, Healthy Eating Food Index, HEFI-2019, choix alimentaires, adhésion, recommandations alimentaires.

\section{Introduction}

Suboptimal dietary patterns are among the leading risk factors for morbidity and mortality in Canada (Alam et al. 2019) and worldwide (G.B.D Risk Factors Collaborators 2020). Healthy eating is therefore a critical component of chronic disease prevention and management. In this regard, several countries have proposed food-based dietary recommendations (Food and Agriculture Organization of the United Nations 2021) that guide consumers towards achieving healthy dietary patterns. National dietary guidelines also present key information for health professionals as well as policy-makers to support strategies that promote healthy eating (Health Canada 2019a). Finally, dietary guidelines are often used as a reference by food services, government programs and the food industry to support the development of healthier food environments.

In 2019, Health Canada released an updated Canada's Food Guide (CFG-2019) that promotes healthy eating and overall nutritional well-being and supports improvements to the food environment (Health Canada 2019b, 2021). Unlike the previous CFG-2007, CFG-2019 no longer provides dietary guidance based on age-sex recommendations for the number of servings per day and servings sizes. Rather, CFG-2019 recommends eating a variety of healthy foods each day, including fruits and vegetables, whole grains and protein foods emphasizing plant-based protein foods more often (Health Canada 2019b). The 2019 Canada's food guide plate is an illustration of the desirable proportions of food categories in relation to one another and can be used as a visual cue or reminder to follow when building healthy meals and snacks. Recommendations in CFG-2019, which are less prescriptive than previous recommendations in Canada, also provide guidance not only on what to eat, but also on how our eating habits and food environments can promote health and reduce the risk of nutrition-related chronic diseases. Healthy food choices and healthy eating habits within CFG-2019 are promoted through a suite of targeted web pages that communicate information to a variety of users including the public, policy-makers and health professionals (Health Canada 2019a). For example, Health Canada's Dietary Guidelines are intended primarily for health professionals and policy-makers, while the Healthy Eating Recommendations and the plate snapshot translate Health Canada's Dietary Guidelines into simple and applicable messages for consumers (Health Canada 2019a).

For research and surveillance purposes, it is important to evaluate the extent to which individuals and populations adhere to dietary guidelines. In this regard, the development of an index reflecting the degree to which patterns of eating align with dietary guidelines is invaluable. Such indices are often used as a proxy measure of overall diet quality and can track temporal trends and changes in population-based studies and in national surveys (Kirkpatrick et al. 2018; Krebs-Smith et al. 2015; Ocke
2013; Wirt and Collins 2009). Specific components of such indices may also be used to assess adherence of the population or subgroups of the population to specific recommendations (Kirkpatrick et al. 2018). Indices reflecting alignment of dietary patterns to dietary guidelines may be used to measure associations between specific dietary recommendations and health outcomes (Krebs-Smith et al. 2015; Liese et al. 2015; Miller et al. 2020), thus providing key data to inform future guidelines. In 2009, Garriguet (2009) developed the Canadian Healthy Eating Index (C-HEI) to measure adherence to recommendations in the CFG-2007. The C-HEI was inspired by the HEI-2005, which was designed to measure adherence to the Dietary Guidelines for Americans 2005 (Guenther et al. 2008). As indicated above, there are fundamental differences in the recommendations found in the 2007 and 2019 versions of CFG. Thus, the C-HEI 2007 could not be used to assess adherence to the most recent dietary recommendations in Canada and the development of an entirely new adherence index was warranted. This paper describes the development and provides a detailed description of the Healthy Eating Food Index 2019 (HEFI-2019), which aims to measure alignment of dietary patterns to the "Healthy Food Choices" recommendations of the CFG-2019 (also referred to as the "What to Eat" recommendations). The evaluation of the HEFI-2019 is presented in an accompanying paper (Brassard et al. 2022).

\section{Materials and methods}

The development of the HEFI-2019 involved 3 steps: 1- a scan of the literature for existing indices, 2- defining general guiding principles and 3- development of the HEFI-2019 components and standards for scoring based on an iterative process.

\section{Literature scan of existing tools}

A scan of the literature was first performed to explore the possibility of adapting or adopting existing dietary guidance adherence indices for use in Canada. The scan also assessed how different countries or organizations approached the development of their dietary guidance adherence indices. Although no existing index was adequately tailored to the content and intention behind each recommendation in the CFG-2019, the scan provided insightful methodological information regarding the development of such indices. Notably, the scan highlighted the challenge of translating flexible and non-quantitative recommendations into scalable standards (Gabe and Jaime 2019). It also provided inspiration to develop a framework that translates recommendations into components of an adherence index (Romaguera et al. 2012; Shams-White et al. 2019). 


\section{Defining guiding principles}

In March 2020, Health Canada in collaboration with the Knowledge Translation Strategy Unit of the Canadian Institutes of Health Research, held a 1-day "Best Brains Exchange" meeting of experts from Canada, the USA and Brazil to initiate the development of different indices to measure adherence to CFG-2019 recommendations. Stakeholders represented a wide array of expertise, including nutrition policy and public health, nutritional epidemiology, implementation research, dietary intake assessment methods and index development and validation. A summary of this event is available online (Canadian Institutes of Health Research and Health Canada 2020). Participants of the meeting agreed that more than 1 dietary guidance adherence index was needed to measure both dimensions of the CFG-2019, i.e., recommendations on healthy food choices and on healthy eating habits. There was also strong consensus among participants regarding the considerations leading to the development of the HEFI-2019 (Box 1).

Participants were invited to provide feedback and comments during the subsequent phases of development of the HEFI-2019, described below, and its evaluation (Brassard et al. 2022).

\section{Key sources of information considered}

The HEFI-2019 aims to measure alignment of dietary patterns, hence adherence, to the "Healthy Food Choices" recommendations in the CFG-2019. It was agreed that the HEFI-2019 be developed for an application to 24-hour dietary recall data, since 24-hour dietary recall is considered the best dietary assessment instrument for use in population-based and national surveys (Thompson et al. 2015).

The primary source of information was CFG-2019. In particular, individual components of the HEFI-2019 and the overall index needed to be fully aligned with the wording and intention behind each healthy food choice recommendation in CFG-2019. Other sources of information were data-based evidence and expert judgement. Data-based evidence included the literature scan of existing tools described above as well dietary intake data among Canadians based on the 2015 Canadian Community Health Survey (CCHS)Nutrition. The 2015 CCHS-Nutrition is the most recent national nutrition survey conducted in Canada and provides data on foods and nutrient intakes as well as other data to support interpretation of dietary intake information. Data from the 2015 CCHS-Nutrition was used to inform aspects of the scoring standards, along with the comparison of scoring standards with dietary intakes of Canadians. The simplicity of use of the HEFI-2019 and consistency in the definition of all components of the index were identified as overarching guiding principles. The HEFI-2019 also needed to demonstrate satisfactory psychometric properties (Bland and Altman 2002; Kirkpatrick et al. 2019). Those were examined in a concurrent study (Brassard et al. 2022).

Information in CFG-2019 included (i) Canada's Dietary Guidelines, primarily targeting health professionals and policy-makers (Health Canada 2019a); (ii) the Healthy Eating Recommendations, primarily targeting consumers (see Appendix A in Health Canada 2019a); and (iii) the Food Guide Snapshot (Health Canada 2019b). Canada's Dietary Guidelines encompass 3 main guideline components. Guidelines \#1 and \#2 relate to the foundation of healthy eating and foods and beverages that undermine healthy eating, respectively. Guideline \#3 relates to healthy eating habits ("how to eat") and was not considered in the present work.

\section{Identification of the HEFI-2019 components}

Table 1 presents the key recommendations on healthy food choices in CFG-2019 and how they were translated into the corresponding components of the HEFI-2019. Based on the alignment with key recommendations, 10 components were identified, of which 5 are based on foods, 1 on beverages, and 4 on nutrients.
Box 1. Key considerations towards the development of the HEFI-2019.

- Have clearly defined guiding principles for decision-making

- Include all recommendations on healthy food choices in CFG-2019

- Have clear definitions of each component score and accompanying documentation on the interpretation of the total HEFI-2019 score and component scores

- Rationalize the attribution of equal or unequal number of points to each of the components of the HEFI-2019 (i.e., whether or not the components should receive equal points)

- Ensure that the HEFI-2019 has satisfactory psychometric properties

- The final decisions regarding each component's justification, structure and scoring standard of the HEFI-2019 would rest with Health Canada

- Update subsequent versions of the HEFI-2019 (with future revisions of the CFG) only if significant changes are required

The broad recommendation that "nutritious foods are the foundation for healthy eating" was not assessed independently.

Seven of the HEFI-2019 components are "adequacy" components, i.e., greater adherence is defined by greater relative consumption, while 3 components are "moderation" components that relate to nutrients of concern, namely saturated fats, free sugars and sodium (Table 1), for which greater adherence is defined by lower relative consumption. CFG-2019 neither dissuades nor encourages the consumption of sugar substitutes or artificial sweeteners (Table 1) and further indicates that nutritious foods and beverages should be promoted instead of artificially or sugar-sweetened foods and beverages (Health Canada 2019a). The recommendation related to sugar substitutes is captured in the Beverages component, since artificially sweetened beverages are important contributors to the intake of sugar substitutes. Alcohol consumption is also considered in the Beverages component.

\section{Reference metrics to assess proportionality of food-based recommendations}

As indicated above and unlike previous editions, CFG-2019 does not provide specific guidance on food portion size and recommended servings per day. Although the proportions of vegetables and fruits (50\%), whole-grain foods (25\%) and protein foods $(25 \%)$ in the CFG-2019 plate's snapshot are not specific quantitative targets per se, they were used as a benchmark to develop the HEFI2019. Components expressed as ratios of intakes (i.e., densities or proportions) are more likely to reflect the quality of foods rather than the quantity, which is desirable for an adherence index (Krebs-Smith et al. 2018). Different options were considered to represent the proportions of the various food categories within an eating pattern, including volumes, weights and reference amounts (RAs). Using volumes is challenging since some solid foods such as whole fruits or muffins, cannot easily be expressed in volumes. Using weights was also ruled out because consumption of nutritionally dense foods (e.g., leafy greens) and energydense foods (e.g., nuts) cannot be easily compared based on weights. RAs were therefore chosen as the metric to assess the proportional nature of the recommendations on healthy food choices in CFG-2019. RAs represent the amount of food (grams for solid foods, ml for liquids), typically consumed in 1 sitting and are available for most foods in Canada (Health Canada 2016). The use of RA as a reference unit to translate each food-based recommendation into a scalable metric also circumvented the absence of recommended numerical amounts of food for each food category in CFG-2019. All food-based components expressed in RAs (Vegetable and fruits, Whole-grains foods, Grains foods ratio, Protein foods, Plant-based protein foods) are calculated as 
Table 1. Key healthy food choices recommendations in CFG-2019 and corresponding components of the HEFI-2019.

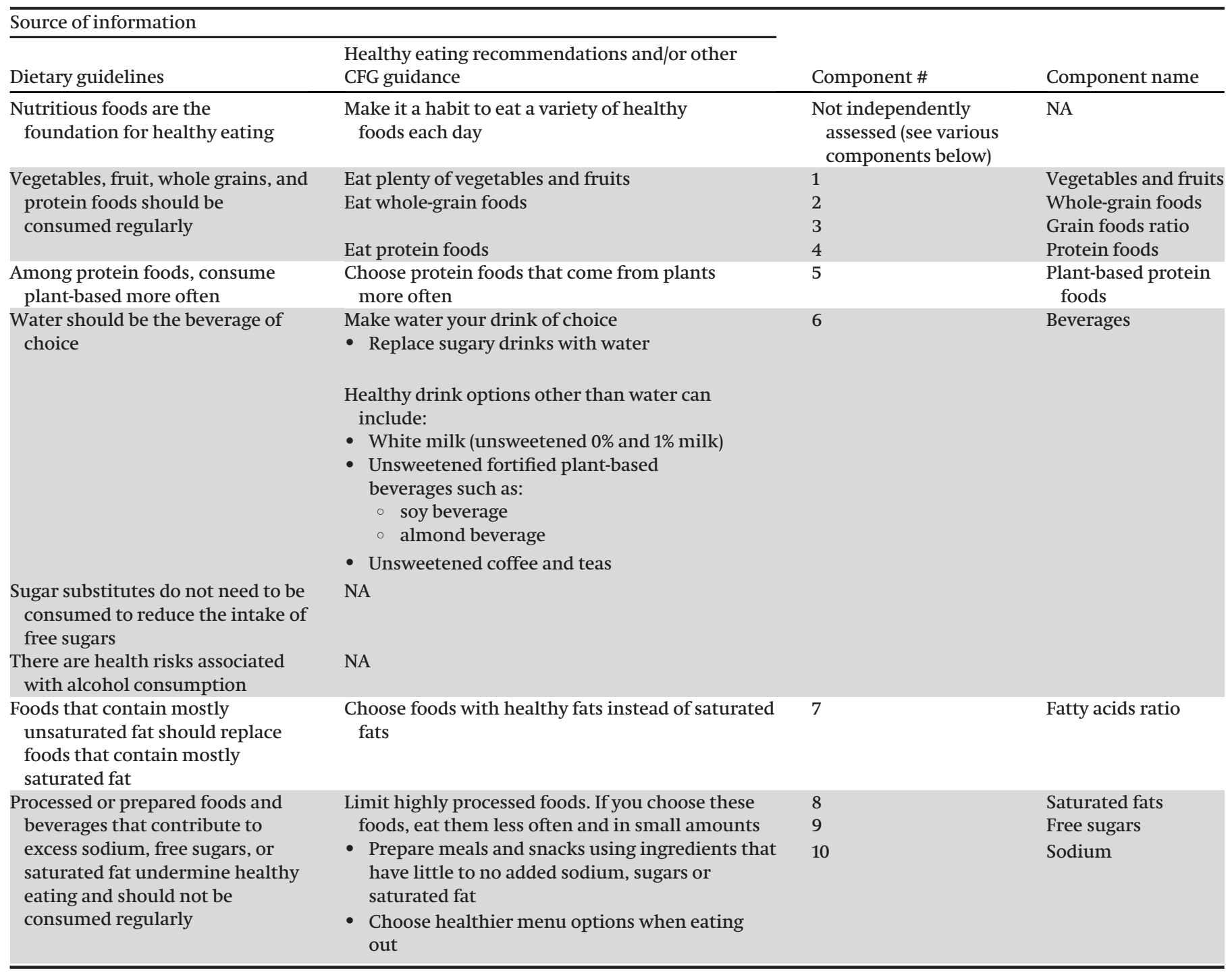

Note: CFG, Canada's Food Guide; HEFI-2019, Healthy Eating Food Index; NA, not applicable.

ratios to all (total) foods consumed, also expressed as RAs. Total foods consumed include all vegetables and fruits, all whole- and non-whole-grains foods as well as all protein foods, including unsweetened and protein-rich beverages $(>2.5 \mathrm{~g}$ protein $/ 100 \mathrm{~mL}$; Health Canada 2002), which are considered protein foods in the CFG-2019. Total foods also include all foods not recommended in CFG-2019 such as processed or prepared foods (e.g., processed meats, sugary breakfast cereals, biscuits and cakes, confectioneries). The amount for total foods is calculated by adding up the number of RAs of all foods consumed. Culinary ingredients (e.g., spices, baking soda), beverages without protein (e.g., water, coffee, tea, almond, cashew, rice, coconut) as well as oils and spreads are not included in the calculation of total foods. Beverages without protein are accounted for in the Beverages component. Oils and spreads are accounted for in the calculation of the nutrientbased Fatty acids ratio and Saturated fats components. Table A1 in Appendix A provides complete details about which foods and beverages are considered in each component of the HEFI-2019.

\section{Reference metrics to assess the sodium component}

The CFG-2019 sets the recommended limit for sodium at the $2300 \mathrm{mg} /$ day chronic disease risk reduction threshold established by the National Academies of Sciences, Engineering, and Medicine
(NASEM) (National Academies of Sciences Engineering Medicine 2019). As such, one would opt to use absolute sodium intake values to score this component. However, sodium and energy intakes are strongly correlated (Health Canada 2018b; World Health Organization 2012). Using absolute sodium intake to calculate the Sodium component increases the likelihood of a strong association between the HEFI-2019 score and total energy intakes, and thus with the amount of food consumed as well, which is not consistent with the index' purposes.

On the other hand, using a density approach attenuates the association between energy intake and indices of diet quality (Krebs-Smith et al. 2018; Reedy et al. 2018), thus yielding an index that is less reliant on the amount of foods consumed. Other advantages of using the density approach are a higher sensitivity to detect changes over time due to smaller "ceiling" and "floor" effects and consistency of scoring standards among all components of the HEFI-2019, which are calculated as ratios of all foods or beverages consumed or the percentage of total energy (\%E).

\section{Weighting of components}

As indicated above, a total of 10 components were mapped to healthy food choices recommendations in CFG-2019 (Table 1). One 
option considered was to attribute the same number of points to each component. However, some components are addressed by complementary recommendations in CFG-2019. For example, the components Protein foods and Plant-based protein foods both relate to protein foods in the diet. Had both components been scored equally (i.e., 10 points each), recommendations on protein foods would have had more weight in the total HEFI-2019 (i.e., 20/ 100 points) than other individual recommendations, e.g., Beverages (10/100 points). To achieve equal weighting of individual vs. sets of 2 complementary components, the latter received 5 points each, so that their combined weight was equal to other single component or sets of related components in the total HEFI-2019 score. As shown below, this was the case for 3 sets of complementary recommendations: the 2 protein-related components, the 2 grains-related components and the 2 fat-related components. The only exception to the equal weighting approach pertained to the vegetables and fruits recommendation, for which there is substantial evidence and little debate as to their importance in healthy dietary patterns (Health Canada 2019b, 2019c). For this reason and as detailed below, the Vegetables and fruits component was weighted more heavily (20 points) than all other components or sets of components (up to 10 points). The total HEFI-2019 is scored on a scale of 0 to 80 points.

\section{Statistical analyses}

Dietary intake data for Canadians aged 2 years and older measured using 24-hour dietary recalls were obtained from the 2015 CCHS-Nutrition to guide decisions around the HEFI-2019 components and scoring. Complete details of the survey methods are presented elsewhere (Brassard et al. 2022; Health Canada 2017). First, distributions of intakes on a given day (i.e., first 24-hour recall) were estimated to derive scoring standards in the absence of a benchmark in CFG-2019 or of empirical data supporting specific limits. This was the case for the HEFI-2019 components Fatty acids ratio, Free Sugars, Saturated fats and Sodium.

Second, distributions of usual intakes (i.e., long-term average) were estimated to compare scoring standards to dietary intakes of Canadians aged 2 years and older. Repeated 24-hour dietary recalls were collected in approximately 37\% of the 2015 CCHSNutrition respondents. Taking advantage of the repeated 24-hour dietary recalls, usual intake distributions of foods and nutrients among Canadians were estimated using the National Cancer Institute's bivariate method (Freedman et al. 2010; Kipnis et al. 2016). The models were stratified according to age and sex to better reflect random variations in intake. The 3 strata used were children and adolescents 2-18 years, males 19 years and older and females 19 years and older. Estimated intakes among pseudoindividuals generated in the Monte Carlo simulation step within each stratum were pooled before estimating distribution of intakes in the overall sample. The covariates included in the models were age, categorized according to Dietary Reference Intake groups, sex (only for 2-18 years), an indicator variable for sequence of 24-hour recalls (first or second when appropriate) and an indicator variable weekend days (Friday, Saturday, Sunday). All analyses were weighted with survey weights provided by Statistics Canada. Secondary analyses conducted using data from the 2015 CCHS-Nutrition conducted by Statistics Canada do not require additional ethics approval.

\section{Results}

Table 2 presents the HEFI-2019 components, points allocated and the standards for scoring according to thresholds for each component. Points between the minimum and maximum scores are attributed proportionately for all components.

\section{Component \#1: Vegetables and fruits}

The component is calculated as the ratio of vegetables and fruits (expressed in RAs) to total foods (also expressed in RAs). The $50 \%$ proportion of vegetables and fruits in the CFG-2019 snapshot is used as a benchmark to assess adherence to this recommendation. The Vegetables and fruits component refers to whole, dried and canned vegetables and fruits, regardless of their saturated fat, free sugar or sodium content, which are assessed separately. All types of potatoes irrespective of preparation method (e.g., oven-cooked, boiled, fried) are also included (Table A1). Fruit juices are excluded because they are considered sugary drinks in CFG-2019. Maximum points (20 points) are given when the ratio of vegetables and fruits in RAs to total foods in RAs is equal to or greater than 0.5 or $50 \%$, indicating that half or more of all foods consumed are vegetables and fruits. Minimum points ( 0 points) are given when the consumption of vegetables and fruits equals 0 . As shown in Fig. 1 and based on usual dietary intake data among Canadians aged 2 years and older, the $50 \%$ cut-off allows for a score distribution that is not limited by an important "ceiling" or "floor" effect (i.e., very few individuals receive maximum or minimum points).

\section{Components related to grain foods}

Adherence to the recommendation related to whole-grain foods is assessed using 2 components (components \#2 and \#3), which add up to a total of 10 points in the HEFI-2019. The first of these 2 components captures the amount (quantity) of wholegrain foods relative to total foods consumed. The second of these 2 components captures the quality of all grains consumed, i.e., whether they are whole or not. Assessing whole-grain consumption both from a relative quantity (component \#2) and a relative quality perspective (component \#3) ensures that diets very low in grain foods do not receive maximum points, even when only small amounts of whole-grain foods are consumed.

\section{Component \#2: Whole-grain foods}

The Whole-grain foods component is scored as the ratio of whole-grain foods measured in RAs to total foods measured in RAs. Whole-grain foods include all foods in which the first ingredient is a whole grain or whole wheat. All whole-grain and wholewheat foods are included regardless of their saturated fat, free sugar or sodium content. The $25 \%$ proportion of whole-grain foods on CFG-2019 snapshot is used as a benchmark, with ratios $\geq 0.25$ receiving the maximum of 5 points. The minimum score ( 0 point) is given when no whole-grain foods are consumed. As shown in Fig. 1, the 0.25 cut-off for maximum points allows for a score distribution that has no "ceiling" or "floor" effect.

\section{Component \#3: Grain foods ratio}

The second of the 2 components related to recommendations on whole grains in CFG-2019 is calculated as the ratio of wholegrain foods to the sum of all grain foods, both measured in RAs. The numerator of this component is the same as the numerator of the Whole-grain foods component (component \#2). The denominator includes all foods in which the first ingredient is a grain (whole or not), regardless of their saturated fat, free sugar or sodium content. A ratio equal to 1 indicates that all grain foods consumed are whole-grain, aligned with CFG-2019 recommendations (Table 1), and is given the maximum of 5 points, while the minimum score ( 0 point) is given when no whole-grain foods are consumed. No consumption of grain foods (whole or not) is also given 0 points.

\section{Components related to protein foods}

Adherence to recommendations on dietary proteins is also assessed using 2 components to reflect relative quantity (component \#4) and quality (component \#5). Each component is given a maximum score of 5 points, for a maximum total of 10 points for the 2 protein-related components. Component \#4 assesses alignment with the recommendation targeting total protein food consumption as shown in the CFG-2019 snapshot. Component \#5 assesses alignment with the recommendation targeting plant-based protein food consumption. 
Table 2. HEFI-2019 components, points and standards for scoring.

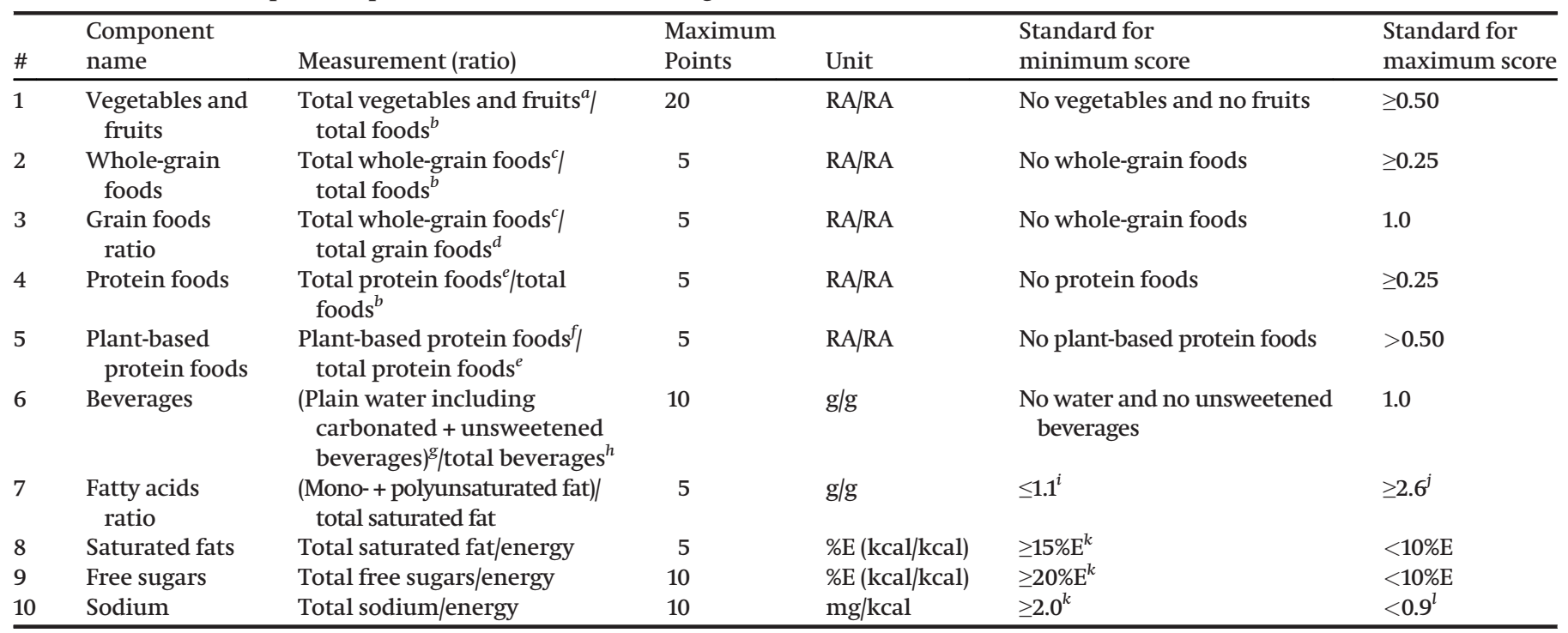

Note: CCHS, Canadian Community Health Survey; CDRR, Chronic Disease Risk Reduction; CFG, Canada's Food Guide; HEFI, Healthy Eating Food Index; RA, Reference Amounts (amount of food usually eaten by an individual at 1 sitting, defined as the Table of Reference Amounts in Health Canada 2016); \%E, percent of total energy.

${ }^{a}$ All vegetables and fruits regardless of saturated fat, sodium or free sugar content; excludes fruit juice (i.e., considered as sugary drinks in CFG-2019).

${ }^{b}$ Includes all foods consumed as well as beverages considered in protein foods (i.e., unsweetened milk and unsweetened plant-based beverages that contain protein); excludes all other beverages as well as solid fats, oils and spreads and culinary ingredients (e.g., spices and baking soda).

${ }^{c}$ Foods where the first ingredient is either whole grains or whole wheat, regardless of saturated fat, sodium or free sugar content.

${ }^{d}$ Foods where the first ingredient is a grain (whole or not) regardless of saturated fat, sodium or free sugar content.

${ }^{e}$ All protein foods regardless of fat, sodium or sugars content; excludes processed meats (i.e., not considered protein foods in CFG-2019) and sweetened milks (i.e., considered as sugary drinks in CFG-2019).

${ }^{f}$ All plant-based protein foods, regardless of saturated fat, sodium or free sugar content.

${ }^{g}$ Unsweetened beverages include unsweetened coffee and tea, unsweetened milk and unsweetened plant-based beverages.

${ }^{h}$ Total beverages include water (plain or carbonated), coffee, tea, milk and plant-based beverages, fruit and vegetable juices, alcoholic drinks, artificially sweetened beverages and sugary drinks.

${ }^{i}$ Approximately the $15^{\text {th }}$ percentile of intake based on data (single 24-hour recall) in Canadians from the 2015 CCHS-Nutrition.

${ }^{j}$ Corresponds to the $1^{\text {st }}$ percentile of unsaturated to saturated fats ratios among simulated diets developed to be fully consistent with all recommendations in CFG-2019.

${ }^{k}$ Approximately the $85^{\text {th }}$ percentile of intake based on data (single 24-hour recall) in Canadians from the 2015 CCHS-Nutrition.

${ }^{l}$ Standard for maximum points based on the CDRR for $14 \mathrm{y}$ and older (i.e., $2300 \mathrm{mg}$ ) over the $90^{\text {th }}$ percentile of usual energy intakes in respondents aged $2 \mathrm{y}$ and older from the 2015 CCHS-Nutrition (i.e., approximately $2600 \mathrm{kcal}$, see Methods for detail).

\section{Component \#4: Protein foods}

The Protein foods component is calculated as the ratio of protein foods measured in RAs to total foods measured in RAs. Protein foods include fish, shellfish, eggs, poultry, red meat, dairy foods and plant-based protein foods (e.g., legumes, nuts, seeds, tofu) (Table A1). Even though CFG-2019 recommends consuming lean red meat, lower fat milk, yogurts, kefir, and cheeses lower in fat and sodium, all protein foods are included in the Protein foods component regardless of their saturated fat, free sugar and sodium content, which are considered separately. Unsweetened milk and unsweetened (fortified or not) plant-based beverages (proteins $>2.5 \mathrm{~g} / 100 \mathrm{~mL}$ ) are considered as protein foods in CFG2019 and thus are included in this component, irrespective of fat and sodium content. Sugar-sweetened milk and sugar-sweetened plant-based beverages with proteins are considered sugary drinks in CFG-2019 (Health Canada 2019a). Thus, the intake of these sugary drinks is not considered in the Protein foods component (neither in the numerator nor the denominator), but is rather considered in the Beverages component. Processed meats, which are not considered as protein foods in CFG-2019, are accounted for only in the denominator of this component.

The proportion of protein foods in the CFG-2019 snapshot (25\%) is used as a benchmark to define the scoring standards. Thus, ratios $\geq 0.25$ are given the maximum of 5 points, while the minimum score ( 0 point) is given when no protein foods are consumed. Of note, this scoring scale creates an important ceiling effect, with close to $50 \%$ of Canadians 2 years and older receiving the maximum score for this component in 2015 (Fig. 1).

\section{Component \#5: Plant-based protein foods}

The CFG-2019 recommends to "choose protein foods that come from plants more often". To derive workable scoring rules, "more often" was interpreted as more than half $(>50 \%)$ of all protein foods consumed as being plant-based. All plant-based protein foods are included in the numerator of this component, regardless of their saturated fat, free sugar or sodium content. Unsweetened (fortified or not) plant-based beverages $(>2.5$ g protein/ $100 \mathrm{~mL}$ ) are also included in the numerator, regardless of their saturated fat or sodium content. The denominator of this component is the total protein foods, as described above (numerator of component \#4). A ratio of plant-based protein foods measured in RAs to total protein foods measured in RAs $>0.50$ is given the maximum number of points for this component ( 5 points). The minimum score ( 0 point) is given when no plant-based protein foods are consumed. This component also receives 0 point when no protein foods (plant-based or not) are consumed.

\section{Component \#6: Beverages}

CFG-2019 emphasizes the importance of water as the beverage of choice, but healthy beverage guidance also includes unsweetened lower fat milk, unsweetened (fortified or not) plant-based 
Fig. 1. Estimated cumulative distributions of each component of the HEFI-2019 as well as scoring standards (thresholds for minimum and maximum points, vertical dashed lines), based on usual intake data in Canadians aged 2 years and older (2015 CCHS-Nutrition). The National Cancer Institute bivariate method was used to estimate distributions of usual intakes for each component. CCHS, Canadian Community Health Survey; HEFI, Healthy Food Choice Index; Max., maximum; pts, points; \%E, percent of total energy.
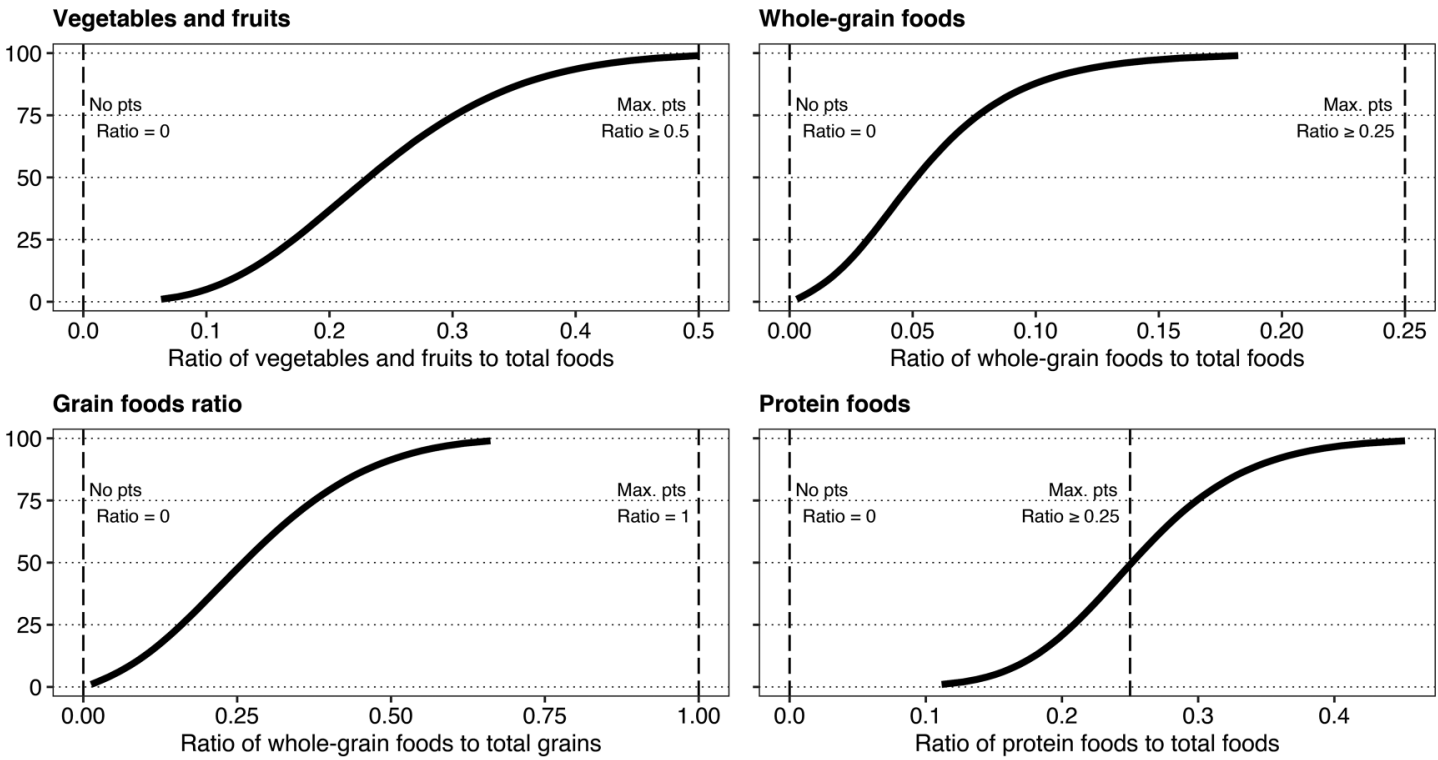

Protein foods

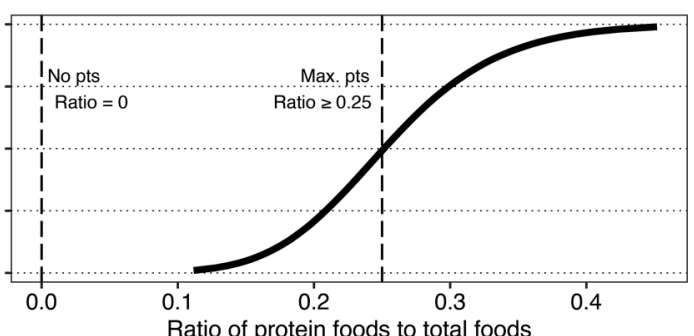

Plant-based protein foods

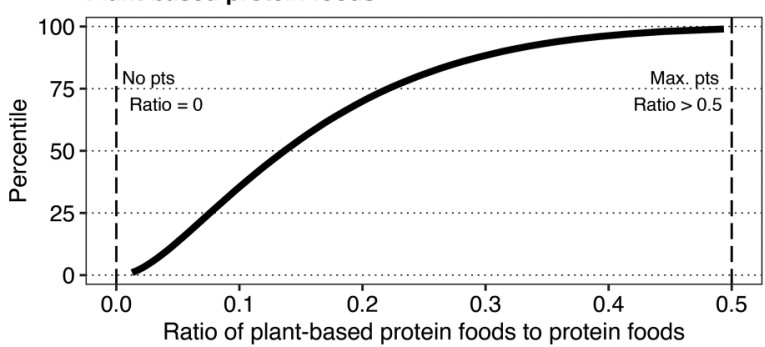

Beverages

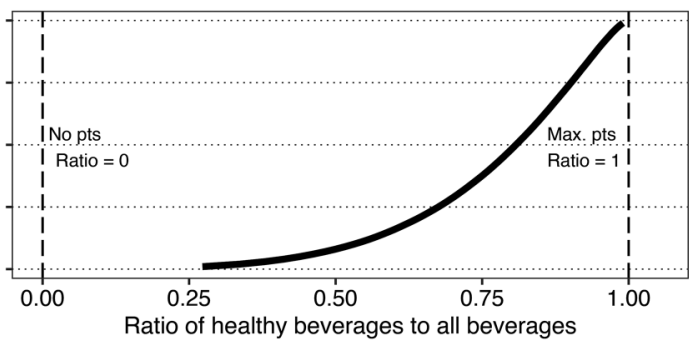

Fatty acids ratio

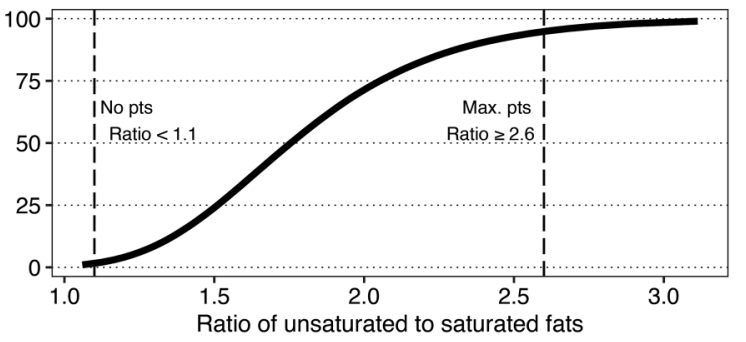

Saturated fats
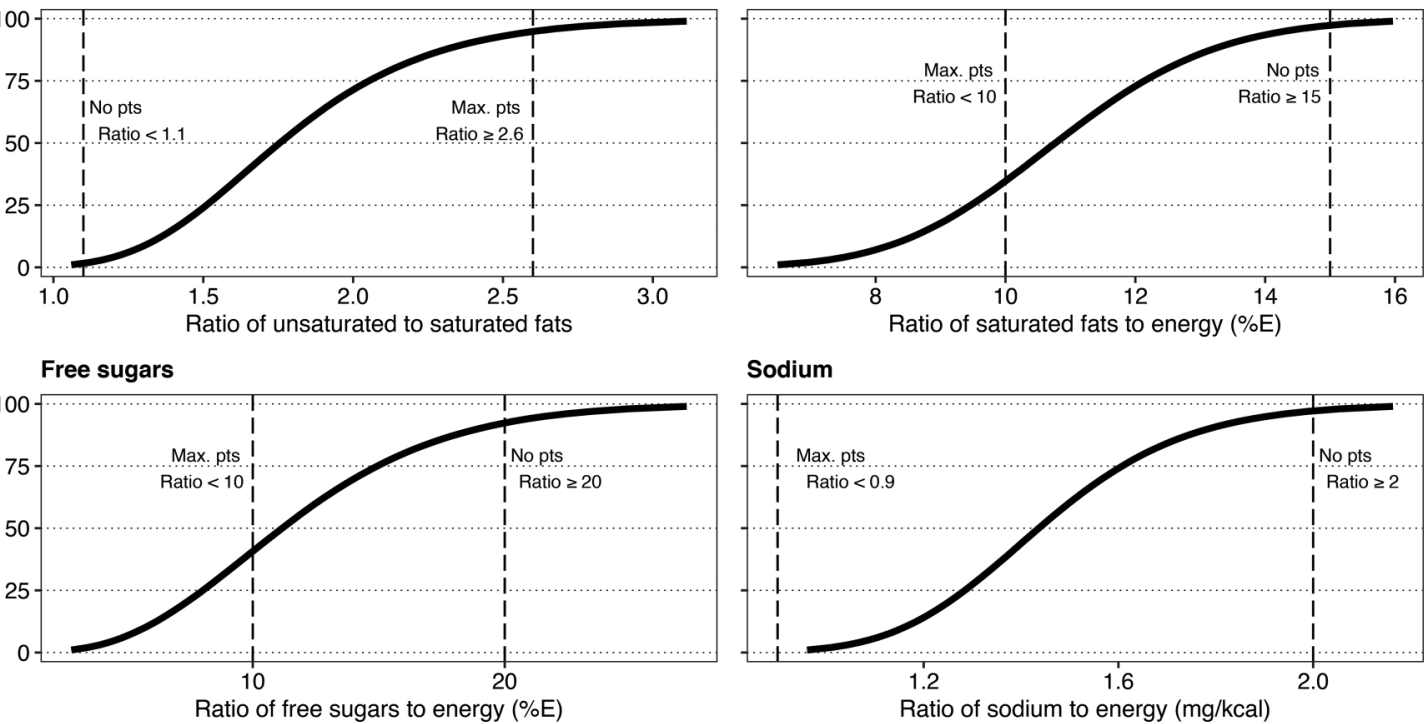

beverages and unsweetened coffee and tea. The main intention behind the recommendation on healthy beverages is that Canadians replace sugary drinks by healthy beverages.

The Beverages component is calculated as the ratio of water and other unsweetened beverages to all beverages, all converted

in grams of intake, to avoid an unnecessary calculation in the number of RAs. Specifically, the numerator of this component includes plain water (including carbonated), unsweetened tea or coffee, unsweetened milk (irrespective of fat content or sodium content) and unsweetened plant-based beverages (fortified or not; 
irrespective of fat or sodium content). Regular fat milk (3.25\% fat) is included in the numerator of this component because the main intent behind the recommendation is to reduce consumption of sugary drinks and because intake of saturated fats is accounted for in 2 other components. The denominator of the Beverages component's ratio includes all of the above plus all sugary drinks such as sodas, sugar-sweetened milks and sugar-sweetened plant-based beverages (i.e., beverages that can contribute to excess free sugars (Health Canada 2019a)), artificially sweetened beverages (including plant-based beverages) and alcohol. Excluding artificially sweetened beverages from the numerator of the Beverages component was justified by the fact that there is no evidence of health benefits associated with the consumption of such beverages (Dietary Guidelines Advisory Committee 2015; World Cancer Research Fund/American Institute for Cancer Research 2018) and because CFG-2019 states that nutritious foods and beverages that are unsweetened should be promoted instead of artificially sweetened beverages (Health Canada 2019a).

There are no prespecified standards to score this component in CFG-2019. An ideal consumption is $0 \mathrm{~g}$ per day of sugary drinks, artificially sweetened beverages or alcohol. The standard is therefore based on no consumption of such drinks. Maximum points for the beverage component (10 points) are given when the ratio = 1.0 , and minimum points ( 0 points) are given when all beverages consumed are sugary drinks, artificially sweetened beverages and alcohol.

\section{Components related to fats}

The CFG-2019 has several recommendations that aim to limit the consumption of saturated fats and increase the consumption of unsaturated fats. The HEFI-2019 comprises 2 components that are related to saturated fat intake (components \#7 and \#8). Component \#7 is calculated as the ratio of unsaturated to saturated fats and captures the recommendations that "Foods that contain mostly unsaturated fat should replace foods that contain mostly saturated fat" and to "Choose foods with healthy fats instead of saturated fat" (Health Canada 2019b). This approach is consistent with the supporting evidence for this recommendation (Health Canada 2019c). Component \#8 captures the recommendation to limit intakes of saturated fats below 10\%E. Each of the 2 components is scored on a scale of 0 to 5 , so that the total number of points related to saturated fats in the HEFI-2019 is 10, consistent with the relative weight given to other nutrients of concern in the HEFI-2019.

\section{Component \#7: Fatty acids ratio}

The score of this component is based on the ratio of unsaturated fat to saturated fat (both measured in grams). A ratio of unsaturated to saturated fat $\geq 2.6$ is given 5 points. This threshold for maximum points corresponds to the $1^{\text {st }}$ percentile of the unsaturated to saturated fat ratio in simulated diets that align with CFG-2019 recommendations (Health Canada, personal communication, unpublished data, 2021). This threshold is also consistent with the threshold used in the HEI-2015 (Guenther et al. 2013; Krebs-Smith et al. 2018). There is no evidence to determine a lower threshold for the unsaturated to saturated fat ratio. To limit a floor effect (i.e., many individuals getting 0 points) and consistent with the methodology employed for the HEI-2015 (Guenther et al. 2013; Krebs-Smith et al. 2018), the $15^{\text {th }}$ percentile of the unsaturated/ saturated fats ratio distribution among Canadians (first 24-hour recall, 2 years and older; 2015 CCHS-Nutrition) corresponding to a ratio of 1.1 is used as the standard for scoring 0 points.

\section{Component \#8: Saturated fats}

This component is calculated as the percentage of energy (\%E) from saturated fats, with maximum points ( 5 points) for values
$<10 \% \mathrm{E}$ as per the recommendation in CFG-2019. There is no empirical data supporting an upper limit for saturated fat intake. The various iterations of the US HEIs (Guenther et al. 2008, 2013; Krebs-Smith et al. 2018) used the $85^{\text {th }}$ percentile of saturated fat intake (as \%E) in NHANES based on dietary intake data from one 24-hour recall to determine the upper limit for the minimum score of 0 points. Consistent with this approach, the $85^{\text {th }}$ percentile of the distribution of saturated fat intakes among Canadians in the 2015 CCHS-Nutrition (first 24-hour recall; 2 years and older) is used (Fig. 1). This corresponds to a saturated fat intake $\geq 15 \% \mathrm{E}$.

\section{Component \#9: Free sugars}

Free sugars are also considered a nutrient of concern in CFG2019 with the recommendation that intake should be below $10 \% \mathrm{E}$. Intakes below this limit receive the maximum number of points (10 points). There is no accepted threshold for maximal free sugars intake. Similar to the Saturated fats component, the standard is based on the $85^{\text {th }}$ percentile of the distribution of free sugars intake among Canadians in the 2015 CCHS-Nutrition (first 24 -hour recall; 2 years and older), i.e., $\geq 20 \%$ E. The Canadian Nutrient File (Health Canada 2018a), from which the dietary intake data are calculated in 2015 CCHS-Nutrition, does not include information on free sugars. However, Health Canada has constructed a database of the free sugars content for foods and ingredients included in the Canadian Nutrient File v2015 (Rana et al. 2021).

\section{Component \#10: Sodium}

As described in the methods, the Sodium component is calculated using a density (energy-adjusted) approach. Using such an approach requires that the cut-off for maximum points needs to be set to a specific amount of energy intake. The HEI-2015 set the $2300 \mathrm{mg} /$ day cut-off for the sodium component to the median energy intake of the US population (Krebs-Smith et al. 2018). Transposed to the Canadian context (median energy intake in Canada according to data from the 2015 CCHS-Nutrition), the $2300 \mathrm{mg} /$ day cut-off for maximum points for the Sodium component would be set at $1800 \mathrm{kcal} /$ day. This implies that maximum points may be given to individuals with sodium intakes exceeding $2300 \mathrm{mg} /$ day. For example, someone reporting $2500 \mathrm{kcal} / \mathrm{day}$ would get 10 points for the Sodium component if the corresponding sodium intake was approximately equal to or below $3200 \mathrm{mg} /$ day. To limit the proportion of individuals receiving maximum points for the Sodium component when sodium intake is greater than $2300 \mathrm{mg} / \mathrm{day}$, the scoring standard for maximum points of the HEFI-2019 is set at the $90^{\text {th }}$ percentile (i.e., $2600 \mathrm{kcal} / \mathrm{day}$ ) of the usual energy intake distribution in the 2015 CCHS-Nutrition in participants aged 2 years and older. As a result, no more than $10 \%$ of the population (those above the $90^{\text {th }}$ percentile of the energy intake distribution) may get maximum points even with sodium intakes above $2300 \mathrm{mg} /$ day. This also implies that the scoring standard for the Sodium component is stringent because the cut-off for maximum points declines proportionately to energy intake. Maximum points are attributed to the Sodium component when the ratio of sodium to energy intake is $<0.9(2300 \mathrm{mg} / 2600 \mathrm{kcal})$. The standard for minimum points is based on the $85^{\text {th }}$ percentile of the sodium to energy intake ratio distribution, based on data from the 2015 CCHSNutrition (first 24-hour recall; 2 years and older), i.e., a ratio $\geq 2$.

\section{Discussion}

\section{Interpretation of the HEFI-2019}

This paper describes the development of the HEFI-2019, which is designed to measure alignment of eating patterns to recommendations on healthy food choices in CFG-2019. The index has a maximum of 80 points when scores of each of the 10 components are summed up. All components are based on ratios to either total 
food, beverage or energy intake, so that the overall HEFI-2019 reflects adherence to recommendations on food choices rather than amount of food consumed (Brassard et al. 2022).

Three basic steps are needed before calculating the HEFI-2019. First, foods and beverages consumed are classified according to the various food and beverage categories used to calculate the numerator and denominator of each of the HEFI-2019 components. Second, the amount of food and beverages for each category, measured in RAs for foods and in grams for beverages, is determined. Third, total intakes of nutrients (mono- and polyunsaturated fats, saturated fats, free sugars measured in grams; sodium, measured in milligrams) and energy (measured in calories) are calculated. This information is used to arrive at the final HEFI2019 score. The scoring algorithm code is presented in supplementary material (Supplementary File $S 1^{1}$ ). The calculation of the HEFI2019 applied to dietary intake data from 24-hour dietary recalls requires the concurrent use of available databases on RAs and on the free sugars content of foods in the Canadian Nutrient File 2015. The Reference Amounts of each food can be found on Government of Canada website (Health Canada 2016). The free sugars estimates of foods in the Canadian Nutrient File can be found elsewhere (Rana et al. 2021).

The scoring standards of the HEFI-2019 components are generally consistent with the actual wording of and intent behind the recommendations on food choices in CFG-2019, with some exceptions. For example, the Beverages component does not directly capture the recommendation that "water be the beverage of choice", but was rather developed to reflect one of the main intents behind the recommendation, that is, to replace the consumption of sugary drinks and artificially sweetened beverages by healthier options. Another example of a slight divergence between scoring standards and the wording of the recommendations pertains to the Protein foods component, in which all proteins foods are included, irrespective of saturated fat, free sugar and sodium content. These nutrients of concern are considered apart from the food-based components of the HEFI-2019, even though the recommendation for Protein foods explicitly recommends the consumption of lower fat protein foods.

Individual components may be used to assess adherence to specific recommendations on food choices in CFG-2019, provided that information on total food, beverage and energy intake is also available. Component scores may also be useful to explain differences between population subgroups or temporal changes in total HEFI-2019 scores. Of note, the component scores for Protein foods, Saturated fats and Free sugars are characterized by non-trivial floor/ceiling effects (see Fig. 1), indicating that important proportions of the Canadian population are already meeting recommendations for these foods and nutrients, as worded in CFG2019. This implies that the Protein Foods, Saturated fats and Free sugars components may be less sensitive to detecting differences among population subgroups or temporal changes. For example, a "perfect" score for the Free sugars component indicates that free sugars intake is below the $10 \% \mathrm{E}$ recommendation in CFG-2019. As such, any difference or temporal change in free sugars intake below this $10 \%$ E cut-off would not be revealed by the Free sugars component score.

\section{Strengths and limitations}

Strengths of this work include the iterative process implemented to develop the HEFI-2019 and consensus among researchers with recognized expertise in dietary intake assessment and in the development of diet quality scores, the alignment of the index with key recommendations in CFG-2019 and the involvement of Health Canada to ensure the index captured the intent of the CFG-2019 recommendations on healthy food choices. Limitations must also be addressed. As indicated above, the presence of floor/ceiling effects for some components may limit the ability of the HEFI-2019 to be sensitive to dietary intake changes that are beyond CFG-2019 recommendations. A specific HEFI-2019 score threshold above which dietary patterns are considered to be fully aligned with CFG recommendations on food choices is currently unknown. Interpreting the HEFI-2019 based on relative differences (e.g., between groups or over time) is therefore recommended to circumvent the lack of a specific score threshold. Considering that the HEFI-2019 has been developed using dietary intake data obtained from 24-hour recalls, more research is needed for its application to data obtained from other comprehensive dietary assessment methods such as FFQ. Finally, the HEFI-2019 does not measure adherence to CFG-2019 recommendations on healthy eating habits, for which other adherence tools are under development.

\section{Conclusion}

The HEFI-2019 has been developed to assess adherence to recommendations on healthy food choices in the updated CFG-2019. Being characterized by satisfactory psychometric properties (see accompanying paper on the evaluation of the tool (Brassard et al. 2022)), the HEFI-2019 does reflect overall diet quality according to these new recommendations. Future research will help reveal the extent to which the HEFI-2019, hence adherence to CFG-2019, is associated with chronic disease risk.

\section{Competing interests statement}

B.L. has the following disclosures: he has received funding from the Canadian Institutes for Health Research (on going), the Fonds de recherche du Québec - Santé (FRQS) (on going), Fonds de recherche du Québec - Nature et technologies (NT) (on going), the Ministère de la santé et des services sociaux (MSSS) du Québec (on going), Health Canada (on-going) and Atrium Innovations (completed in 2019). B.L. is an Advisory Board member of the Canadian Nutrition Society. D.B. has been a casual employee of Health Canada (2019-2020), contributing to the present work and holds a doctoral training award from the Fonds de recherche du Québec - Santé. D.L.O. has received funding from the Canadian Institutes of Health Research, the Social Sciences and Humanities Research Council of Canada, Alberta Innovates, Alberta Blue Cross, the O'Brien Institute for Public Health, the Libin Cardiovascular Research Institute, the Calgary Centre for Clinical Research, the Petro-Canada Young Innovator Award in Community Health, the Canadian Foundation for Dietetic Research and I Can For Kids (a not-for-profit organization). J.V. has received funding on behalf of the Alberta's Tomorrow Project program funding from Alberta Health, Alberta Cancer Foundation, Canadian Partnership Against Canada and Health Canada and in-kind funding from Alberta Health Services as well as project-specific funding from Public Health Agency of Canada and the Canadian Institutes for Health Research; the work described herein represent the views of the authors and not of Alberta's Tomorrow Project or any of its funders. M.L. has received research funding from the Canadian Institutes of Health Research, Sanofi-Pasteur - University of Toronto - Université Paris-Descartes International Collaboration Research Pilot and Feasibility Program, Lawson Centre for Child Nutrition, Public Policy and Child Nutrition, University of Toronto Collaborative Grant, International Development Research Centre, (IDRC), Burroughs-Wellcome Foundation, Heart and Stroke Foundation, and research contracts from the PAHO Regional Office of the WHO, Health Canada, Ontario Public Health Association, Vital Strategies: Resolve to Save Lives Initiative, and the World Health

\footnotetext{
${ }^{1}$ Supplementary data are available with the article at https://doi.org/10.1139/apnm-2021-0415.
} 
Organization. J.H. has received funding from the Canadian Institutes for Health Research, National Institutes of Health, Danone Institute North America, the Canadian Foundation for Dietetic Research, and Health Canada. R.P. has received funding from Health Canada. S.I.K. has received funding from Canadian Institutes of Health Research, the Social Sciences and Humanities Research Council of Canada, Ontario Ministry of Research and Innovation, AI for Good, Health Canada and the National Institutes of Health.

\section{Funding statement}

This work has been partly funded by Health Canada through a contract with Laval University. Health Canada played a significant role in all phases of the work leading to the development of the HEFI-2019.

\section{Contributors' statement}

D.B. and B.L. wrote the first draft of this paper. D.B. was responsible for all statistical analyses. All authors have contributed to this work by providing feedback throughout the development of the HEFI-2019 as well as by critically reviewing this paper. B.L. obtained funding from Health Canada for this work and had final responsibility in finalizing this paper. All authors have read and approved the final version of this manuscript.

\section{Data availability statement}

Data pertaining to the 2015 Canadian Community Health SurveyNutrition (Public Use Microdata Files) are available upon request to Statistics Canada online: https://www150.statcan.gc.ca/n1/en/ catalogue/82M0024X2018001.

\section{Acknowledgements}

Data presented in this article are adapted from Statistics Canada, Canadian Community Health Survey-Nutrition: Public Use Microdata File, 2015, March 2021. This does not constitute an endorsement by Statistics Canada of this product.

\section{References}

Alam, S., Lang, J.J., Drucker, A.M., Gotay, C., Kozloff, N., Mate, K., et al. 2019. Assessment of the burden of diseases and injuries attributable to risk factors in Canada from 1990 to 2016: an analysis of the Global Burden of Disease Study. CMAJ Open, 7(1): E140-E148. doi:10.9778/cmajo.20180137. PMID:30819694.

Bland, J.M., and Altman, D.G. 2002. Statistics Notes: Validating scales and indexes. BMJ, 324(7337): 606-607. doi:10.1136/bmj.324.7337.606. PMID:11884331.

Brassard, D., Elvidge, L.A., St-Pierre, S., Gonzalez, A., Guenther, P.M., Jessri, M., et al. 2022 Evaluation of the Healthy Eating Food Index (HEFI)-2019 measuring adherence to Canada's Food Guide 2019 recommendations on healthy food choices. Appl. Physiol. Nutr. Metab. 47(4): This issue. doi:10.1139/apnm2021-0416.

Canadian Institutes of Health Research and Health Canada. 2020. Developing tools to measure adherence to Canada's new Food Guide. Available from https://irsc-cihr.gc.ca/e/52142.html. [Accessed 31 March 2021.]

Dietary Guidelines Advisory Committee. 2015. Scientific Report of the 2015 Dietary Guidelines Advisory Committee: Advisory Report to the Secretary of Health and Human Services and the Secretary of Agriculture. U.S. Department of Agriculture. Agricultural Research Service, Washington, DC. Available from https://health.gov/our-work/nutrition-physical-activity/ dietary-guidelines/previous-dietary-guidelines/2015/advisory-report. [Accessed 1 November 2021.]

Food and Agriculture Organization of the United Nations. 2021. Food-based dietary guidelines. Available from http://www.fao.org/nutrition/education/fooddietary-guidelines. [Accessed 31 March 2021.]

Freedman, L.S., Guenther, P.M., Dodd, K.W., Krebs-Smith, S.M., and Midthune, D. 2010. The population distribution of ratios of usual intakes of dietary components that are consumed every day can be estimated from repeated 24-hour recalls. J. Nutr. 140(1): 111-116. doi:10.3945/jn.109.110254. PMID:19923394.

Gabe, K.T., and Jaime, P.C. 2019. Development and testing of a scale to evaluate diet according to the recommendations of the Dietary Guidelines for the Brazilian Population. Publ. Health Nutr. 22(5): 785-796. doi:10.1017| S1368980018004123. PMID:30744711.
Garriguet, D. 2009. Diet quality in Canada. Health Rep. 20(3): 41-52. PMID: 19813438.

G.B.D. Risk Factors Collaborators. 2020. Global burden of 87 risk factors in 204 countries and territories, 1990-2019: a systematic analysis for the Global Burden of Disease Study 2019. Lancet, 396: 1223-1249. doi:10.1016/ S0140-6736(20)30752-2. PMID:33069327.

Guenther, P.M., Reedy, J., and Krebs-Smith, S.M. 2008. Development of the Healthy Eating Index-2005. J. Am. Diet. Assoc. 108(11): 1896-1901. doi:10.1016/ j.jada.2008.08.016. PMID:18954580.

Guenther, P.M., Casavale, K.O., Reedy, J., Kirkpatrick, S.I., Hiza, H.A., Kuczynski, K.J., et al. 2013. Update of the Healthy Eating Index: HEI-2010. J. Acad. Nutr. Diet. 113(4): 569-580. doi:10.1016/j.jand.2012.12.016. PMID:23415502.

Health Canada. 2002. Interim Marketing Authorization to permit the optional addition of vitamins and mineral nutrients to plant-based beverages. Available from https://www.canada.ca/en/health-canada/services/food-nutrition/ legislation-guidelines/interim-marketing-authorizations/permit-optionaladdition-vitamins-mineral-nutrients-plant-based-beverages.html. [Accessed 1 May 2021.]

Health Canada. 2016. Nutrition labelling: Table of reference amounts for food. Health Canada, Ottawa, Ont. Available from http://publications.gc. ca/site/fra/9.829061/publication.html. [Accessed 31 March 2021.]

Health Canada. 2017. Reference guide to understanding and using the data: 2015 Canadian Community Health, Survey - Nutrition. 978-0-660-08450-3. Health Canada, Ottawa, Ont. Available from https://www.canada.ca/en/healthcanada/services/food-nutrition/food-nutrition-surveillance/health-nutrition-surveys/ canadian-community-health-survey-cchs/reference-guide-understanding-usingdata-2015.html. [Accessed 31 March 2021.

Health Canada. 2018a. Canadian Nutrient File (CNF) 2015. Health Canada, Ottawa, Ont. Available from https://food-nutrition.canada.ca/cnf-fce/index-eng. jsp.

Health Canada. 2018b. Sodium intake of Canadians in 2017. Health Canada, Ottawa, Ont. Available from https://www.canada.ca/en/health-canada/ services/publications/food-nutrition/sodium-intake-canadians-2017.html. [Accessed 31 March 2021.]

Health Canada. 2019a. Canada's dietary guidelines - for health professionals and policy makers. Health Canada, Ottawa, Ont. Available from https:/ food-guide.canada.ca/en/guidelines/. [Accessed 31 March 2021.]

Health Canada. 2019b. Canada's food guide. Health Canada, Ottawa, Ont. Available from https://food-guide.canada.ca/en/. [Accessed 31 March 2021.]

Health Canada. 2019c. Food, Nutrients and Health: Interim Evidence Update 2018 for Health Professionals and Policy Makers. Health Canada, Ottawa, Ont. Available from https://www.canada.ca/content/dam/hc-sc/documents/ services/canada-food-guide/resources/evidence/food-nutrients-health-interimevidence-update-2018/pub1-eng.pdf. [Accessed 31 March 2021.]

Health Canada. 2021 Revision process for Canada's food guide. Health Canada, Ottawa, Ont. Available from https://www.canada.ca/en/health-canada/services/ canada-food-guide/about/revision-process.html. [Accessed 31 March 2021.]

Kipnis, V., Freedman, L.S., Carroll, R.J., and Midthune, D. 2016. A bivariate measurement error model for semicontinuous and continuous variables: Application to nutritional epidemiology. Biometrics, 72(1): 106-115. doi:10.1111/ biom.12377. PMID:26332011.

Kirkpatrick, S.I., Reedy, J., Krebs-Smith, S.M., Pannucci, T.E., Subar, A.F., Wilson, M.M., et al. 2018. Applications of the Healthy Eating Index for surveillance, epidemiology, and intervention research: considerations and caveats. J. Acad. Nutr. Diet. 118(9): 1603-1621. doi:10.1016/j.jand.2018.05.020. PMID:30146072.

Kirkpatrick, S.I., Baranowski, T., Subar, A.F., Tooze, J.A., and Frongillo, E.A. 2019. Best practices for conducting and interpreting studies to validate self-report dietary assessment methods. J. Acad. Nutr. Diet. 119(11): 18011816. doi:10.1016/j.jand.2019.06.010. PMID:31521583.

Krebs-Smith, S.M., Subar, A.F., and Reedy, J. 2015. Examining dietary patterns in relation to chronic disease: matching measures and methods to questions of interest. Circulation, 132(9): 790-793. doi:10.1161/CIRCULATIONAHA.115.018010. PMID:26260734.

Krebs-Smith, S.M., Pannucci, T.E., Subar, A.F., Kirkpatrick, S.I., Lerman, J.L., Tooze, J.A., et al. 2018. Update of the Healthy Eating Index: HEI-2015. J. Acad. Nutr. Diet. 118(9): 1591-1602. doi:10.1016/j.jand.2018.05.021. PMID:30146071.

Liese, A.D., Krebs-Smith, S.M., Subar, A.F., George, S.M., Harmon, B.E., Neuhouser, M.L., et al. 2015. The Dietary Patterns Methods Project: synthesis of findings across cohorts and relevance to dietary guidance. J. Nutr. 145(3): 393-402. doi:10.3945/jn.114.205336. PMID:25733454.

Miller, V., Webb, P., Micha, R., and Mozaffarian, D. Global Dietary Database. 2020. Defining diet quality: a synthesis of dietary quality metrics and their validity for the double burden of malnutrition. Lancet Planet Health, 4(8): e352-e370. doi:10.1016/S2542-5196(20)30162-5. PMID:32800153.

National Academies of Sciences Engineering Medicine. 2019. Dietary reference intakes for sodium and potassium. Translated from English by The National Academies Press, Washington, DC. doi:10.17226/25353.

Ocke, M.C. 2013. Evaluation of methodologies for assessing the overall diet: dietary quality scores and dietary pattern analysis. Proc. Nutr. Soc. 72(2): 191-199. doi:10.1017/S0029665113000013. PMID:23360896.

Rana, H., Mallet, M.-C., Gonzalez, A., Verreault, M.-F., and St-Pierre, S. 2021. Free sugars consumption in Canada. Nutrients, 13(5): 1471. doi:10.3390/ nu13051471. PMID:33925303. 
Reedy, J., Lerman, J.L., Krebs-Smith, S.M., Kirkpatrick, S.I., Pannucci, T.E., Wilson, M.M., et al. 2018. Evaluation of the Healthy Eating Index-2015. J. Acad. Nutr. Diet. 118(9): 1622-1633. doi:10.1016/j.jand.2018.05.019. PMID:30146073.

Romaguera, D., Vergnaud, A.C., Peeters, P.H., van Gils, C.H., Chan, D.S., Ferrari, P., et al. 2012. Is concordance with World Cancer Research Fund/ American Institute for Cancer Research guidelines for cancer prevention related to subsequent risk of cancer? Results from the EPIC study. Am. J. Clin. Nutr. 96(1): 150-163. doi:10.3945/ajcn.111.031674. PMID:22592101.

Shams-White, M.M., Brockton, N.T., Mitrou, P., Romaguera, D., Brown, S., Bender, A., et al. 2019. Operationalizing the 2018 World Cancer Research Fund/American Institute for Cancer Research (WCRF/AICR) Cancer Prevention Recommendations: A Standardized Scoring System. Nutrients, 11(7): 1572. doi:10.3390/nu11071572. PMID:31336836.

Thompson, F.E., Kirkpatrick, S.I., Subar, A.F., Reedy, J., Schap, T.E., Wilson, M.M., and Krebs-Smith, S.M. 2015. The National Cancer Institute's Dietary Assessment
Primer: A Resource for Diet Research. J. Acad. Nutr. Diet. 115(12): 1986-1995. doi:10.1016/j.jand.2015.08.016. PMID:26422452.

Wirt, A., and Collins, C.E. 2009. Diet quality-what is it and does it matter? Publ. Health Nutr. 12(12): 2473-2492. doi:10.1017/S136898000900531X. PMID: 19335941.

World Cancer Research Fund/American Institute for Cancer Research. 2018. Diet, nutrition, physical activity and cancer: a global perspective. Continuous Update Project Expert Report 2018. American Institute for Cancer Research, Washington. Available from https://www.wcrf.org/wp-content/uploads/2021/ 02/Summary-of-Third-Expert-Report-2018.pdf. [Accessed 1 November 2021.]

World Health Organization. 2012. Guideline: Sodium intake for adults and children. 9789241504836. World Health Organization, Geneva, Switzerland.

Appendix A appears on the following page. 
Table A1. Classification of foods and nutrients according to the HEFI-2019.

\begin{tabular}{|c|c|c|c|c|c|}
\hline \multirow[b]{2}{*}{ HEFI-2019 components } & \multicolumn{5}{|l|}{ Dietary constituents } \\
\hline & $\begin{array}{l}\text { Numerator or } \\
\text { denominator of ratio }\end{array}$ & Inclusion & Details & Exclusion & $\begin{array}{l}\text { Example of foods } \\
\text { equivalent to } 1 \text { reference } \\
\text { amount }\end{array}$ \\
\hline \multirow[t]{5}{*}{ Vegetables and fruits* } & \multirow[t]{5}{*}{$\begin{array}{l}\text { Numerator (vegetables } \\
\text { and fruits) }\end{array}$} & Fruit & All types of fruit, includes fruit purees & $\begin{array}{l}\text { Fruit juice (included in } \\
\text { other beverages } \\
\text { below) }\end{array}$ & Apple, $140 \mathrm{~g}$ \\
\hline & & Dark green vegetables & $\begin{array}{l}\text { All dark leafy greens and other } \\
\text { vegetables that are dark green in } \\
\text { colour }\end{array}$ & & Spinach, $85 \mathrm{~g}$ \\
\hline & & $\begin{array}{l}\text { Deep yellow or orange } \\
\text { vegetables }\end{array}$ & $\begin{array}{l}\text { All carrots, winter squash and other } \\
\text { deep yellow or orange vegetables }\end{array}$ & $\begin{array}{l}\text { Sweet potatoes } \\
\text { (included in starchy } \\
\text { vegetables) }\end{array}$ & Carrots, $85 \mathrm{~g}$ \\
\hline & & Starchy vegetables & $\begin{array}{l}\text { All types of potato, white and yellow } \\
\text { corn, sweet potato, yam, parsnip, } \\
\text { plantain, cassava, bread fruit, taro } \\
\text { root, burdock root and lotus root; } \\
\text { regardless of preparation }\end{array}$ & & Mashed potatoes, $140 \mathrm{~g}$ \\
\hline & & Other vegetables & $\begin{array}{l}\text { All remaining vegetables that do not fit } \\
\text { into any of the other vegetable } \\
\text { subgroups. Includes tomato sauce }\end{array}$ & & Tomato sauce, $62 \mathrm{~g}$ \\
\hline Whole-grain foods* & $\begin{array}{l}\text { Numerator (whole } \\
\text { grain, whole-grain } \\
\text { foods and whole- } \\
\text { wheat foods) }\end{array}$ & $\begin{array}{l}\text { Whole grain, whole- } \\
\text { grain foods and } \\
\text { whole-wheat foods }\end{array}$ & $\begin{array}{l}\text { All whole grains that are } 100 \% \text { whole } \\
\text { grain and all grain products with } \\
\text { whole grain or whole wheat as the } \\
\text { first ingredient }\end{array}$ & & Oatmeal, 40 g dry \\
\hline \multirow[t]{2}{*}{ Grain foods ratio } & $\begin{array}{l}\text { Numerator (whole } \\
\text { grain, whole-grain } \\
\text { foods and whole- } \\
\text { wheat foods) }\end{array}$ & $\begin{array}{l}\text { Whole grain, whole- } \\
\text { grain foods and } \\
\text { whole-wheat foods }\end{array}$ & $\begin{array}{l}\text { All whole grains that are } 100 \% \text { whole } \\
\text { grain and all grain products with } \\
\text { whole grain or whole wheat as the } \\
\text { first ingredient }\end{array}$ & & Oatmeal, 40 g dry \\
\hline & $\begin{array}{l}\text { Denominator (non- } \\
\text { whole-grain and non- } \\
\text { whole-wheat foods) }\end{array}$ & $\begin{array}{l}\text { Non-whole-grain and } \\
\text { non-whole-wheat } \\
\text { foods }\end{array}$ & $\begin{array}{l}\text { All refined grain products that do not } \\
\text { have whole grain or whole wheat as } \\
\text { the first ingredient. Includes } \\
\text { cornmeal, tapioca and other plant- } \\
\text { based starchy items }\end{array}$ & & Bread, $75 \mathrm{~g}$ \\
\hline \multirow[t]{2}{*}{ Protein foods* } & \multirow[t]{2}{*}{$\begin{array}{l}\text { Numerator (plant- } \\
\text { based protein foods) }\end{array}$} & Plant-based yogurts & $\begin{array}{l}\text { Fortified yogurt, yogurt drinks, kefir } \\
\text { and similar products made from } \\
\text { plant-based sources that contain } \\
\text { protein }\end{array}$ & & (Plant-based) yogurt, $175 \mathrm{~g}$ \\
\hline & & $\begin{array}{l}\text { Fortified plant-based } \\
\text { cheeses (that contain } \\
\text { sufficient protein) }\end{array}$ & $\begin{array}{l}\text { All fortified cheese-like products made } \\
\text { from plant-based sources that contain } \\
\text { sufficient protein. The protein content } \\
\text { must be not less than } 25 \mathrm{~g} \text { per } 100 \mathrm{~g} \text { of } \\
\text { food. For products intended to } \\
\text { resemble fresh cheese, the protein } \\
\text { content must be not less than } 15 \mathrm{~g} \text { per } \\
100 \mathrm{~g} \text { of food }\end{array}$ & & (Plant-based) cheese, $30 \mathrm{~g}$ \\
\hline
\end{tabular}


Table A1 (continued).

\begin{tabular}{|c|c|c|c|c|c|}
\hline \multirow[b]{2}{*}{ HEFI-2019 components } & \multicolumn{5}{|l|}{ Dietary constituents } \\
\hline & $\begin{array}{l}\text { Numerator or } \\
\text { denominator of ratio }\end{array}$ & Inclusion & Details & Exclusion & $\begin{array}{l}\text { Example of foods } \\
\text { equivalent to } 1 \text { reference } \\
\text { amount }\end{array}$ \\
\hline & \multirow{14}{*}{$\begin{array}{l}\text { Numerator (animal- } \\
\text { based protein foods) }\end{array}$} & Legumes & $\begin{array}{l}\text { Beans, dried peas, lentils, soybeans and } \\
\text { tofu (excluding soy beverages) (Peanuts } \\
\text { are included in nuts, fresh peas are } \\
\text { included in other vegetables) }\end{array}$ & $\begin{array}{l}\text { Soy beverages (included } \\
\text { in beverages or } \\
\text { protein foods, } \\
\text { depending on sugars } \\
\text { content) }\end{array}$ & Tofu, $85 \mathrm{~g}$ \\
\hline & & Simulated meats & $\begin{array}{l}\text { Simulated meat products such as } \\
\text { veggie/meatless patties, nuggets. } \\
\text { Foods are typically made with protein } \\
\text { isolates }\end{array}$ & & $\begin{array}{l}\text { Simulated meats, } 60 \mathrm{~g} \\
\text { (cooked) }\end{array}$ \\
\hline & & Nuts and seeds & All nuts and seeds, including peanuts & Nuts, $50 \mathrm{~g}$ & \\
\hline & & $\begin{array}{l}\text { Plant-based beverages } \\
\text { (that contain } \\
\text { sufficient protein) }\end{array}$ & $\begin{array}{l}\text { All fortified and non-fortified plant- } \\
\text { based beverages, including soy, that } \\
\text { contain sufficient protein. The } \\
\text { protein content must be } \geq 2.5 \mathrm{~g} / 100 \mathrm{~mL}^{\dagger}\end{array}$ & $\begin{array}{l}\text { Sweetened plant-based } \\
\text { beverages (included } \\
\text { in other beverages } \\
\text { below) }\end{array}$ & Plant-based beverages, $258 \mathrm{~g}$ \\
\hline & & Yogurts and kefir & $\begin{array}{l}\text { Yogurt, yogurt drinks, kefir and similar } \\
\text { products made from the milk of } \\
\text { cows, goats and other animals }\end{array}$ & & Yogurt, $175 \mathrm{~g}$ \\
\hline & & Cheeses & $\begin{array}{l}\text { All types of cheese made from the milk } \\
\text { of animals such as cow, goat and } \\
\text { buffalo cheese. Includes cheese with } \\
\text { ingredients such as herbs, } \\
\text { flavourings, spices }\end{array}$ & & Cheese, $30 \mathrm{~g}$ \\
\hline & & Other milk-based foods & $\begin{array}{l}\text { All types of dairy-based desserts, dairy- } \\
\text { based soups and dairy-based sauces }\end{array}$ & & Fresh dairy desserts, $100 \mathrm{~g}$ \\
\hline & & Red meats & $\begin{array}{l}\text { All beef, pork, lamb and goat meat } \\
\text { from domesticated animals }\end{array}$ & $\begin{array}{l}\text { Processed meats } \\
\text { (included in the } \\
\text { denominator total } \\
\text { foods) }\end{array}$ & Meat, $100 \mathrm{~g}$ (cooked) \\
\hline & & Game meats & $\begin{array}{l}\text { Meat from all wild land and sea } \\
\text { mammals }\end{array}$ & & Meat, $100 \mathrm{~g}$ (cooked) \\
\hline & & Poultry and wild birds & Meat from all types of birds & & Poultry, $100 \mathrm{~g}$ (cooked) \\
\hline & & Eggs & All eggs & & Eggs, $100 \mathrm{~g}$ \\
\hline & & Fish and shellfish & All fish and shellfish & & Fish, $100 \mathrm{~g}$ (cooked) \\
\hline & & Organ meats & $\begin{array}{l}\text { The organs of all wild and } \\
\text { domesticated animals }\end{array}$ & & Meat, $100 \mathrm{~g}$ (cooked) \\
\hline & & Milks & $\begin{array}{l}\text { All animal-based milks such as cow, } \\
\text { goat or buffalo milk as well as milk- } \\
\text { based beverages. Includes skim milk } \\
\text { powder }\end{array}$ & $\begin{array}{l}\text { All sweetened milks } \\
\text { (included in sugary } \\
\text { drinks) }\end{array}$ & Milk, $258 \mathrm{~g}$ \\
\hline
\end{tabular}


HEFI-2019 components

Numerator or

Vegetables and fruits,

Whole-grain foods

and Protein foods

denominator of ratio

Denominator (total

foods)

(a)

要

$\begin{array}{ll}\begin{array}{l}\text { Plant-based protein } \\ \text { foods }\end{array} & \begin{array}{c}\text { Numerator (plant- } \\ \text { based protein foods) } \\ \text { Numerator (animal- }\end{array} \\ & \text { based protein foods) }\end{array}$

based protein foods)

Beverages

Numerator (water and

unsweetened

beverages)

tio

All foods included in
numerators of

numerators of

Vegetables and fruits,

Whole-grain foods

and Protein foods

Non-whole-grain and

non-whole-wheat

All refined grain products that do not

have whole grain or whole wheat as

the first ingredient. Includes

cornmeal, tapioca and other plant-

based starchy items

Condiments, sauces Condiments, non-dairy sauces, pickled

and lower fat

dressings

vegetables, lower fat dressings,

fillings and seasonings with salt and

sugar added

Other snack foods

Higher sugar and/or

Chips, pretzels, extruded snacks.

Includes "sugar free" versions of

these snack foods

higher fat foods

ther fat and/or sugar foods where

the first ingredient is either sugar or

fat

Processed meats

All n

curing salting or the addition,

chemical preservatives

Baby and toddler foods Foods that directed for consumption of infants and toddlers.

Meal replacements and Meal replacements and foods

supplements

considered to be supplements

See above

See above

See above

See above

Water

All plain still waters (tap and bottled),

plain and unsweetened carbonated

waters, with or without flavourings.

Excludes sweetened waters

Unsweetened coffee

Plain and unsweetened coffee and tea

and tea

Plant-based beverages

All fortified and non-fortified

unsweetened plant-based beverages

that contain protein ${ }^{\dagger}$ (e.g., soy) or not

(e.g., almond, cashew, rice, coconut)

Milks

All animal-based milks such as cow,

goat or buffalo milk as well as milk-

Example of foods

equivalent to 1 reference

amount

Exclusion

See above

Unsaturated fats and oils, saturated fats and oils

Bread, $75 \mathrm{~g}$

Dips or spreads, $30 \mathrm{~g}$

Chips or pretzels, $50 \mathrm{~g}$

Sugary drinks

(included in other

beverages below)

Chocolate bars, $40 \mathrm{~g}$

Bologna, 55 g (cooked)

Cereals, $30 \mathrm{~g}$

Meal replacement ready to drink beverage, $266 \mathrm{~g}$

See above

See above

See above

See above

Artificially sweetened

waters (included in

other beverages)

$\mathrm{NA}^{\S}$

$\mathrm{NA}^{\S}$

$\mathrm{NA}^{\S}$

$\mathrm{NA}^{\S}$ 


\begin{tabular}{|c|c|c|c|c|c|}
\hline \multirow[b]{2}{*}{ HEFI-2019 components } & \multicolumn{5}{|l|}{ Dietary constituents } \\
\hline & $\begin{array}{l}\text { Numerator or } \\
\text { denominator of ratio }\end{array}$ & Inclusion & Details & Exclusion & $\begin{array}{l}\text { Example of foods } \\
\text { equivalent to } 1 \text { reference } \\
\text { amount }\end{array}$ \\
\hline & & & $\begin{array}{l}\text { based beverages. Includes skim milk } \\
\text { powder }\end{array}$ & $\begin{array}{l}\text { All sweetened milks } \\
\text { (included in sugary } \\
\text { drinks) }\end{array}$ & \\
\hline & $\begin{array}{l}\text { Denominator (all other } \\
\text { types of beverages) }\end{array}$ & Fruit juice & $\begin{array}{l}\text { All fruit juices without added sugars } \\
(100 \%)\end{array}$ & & $\mathrm{NA}^{\S}$ \\
\hline & & Vegetable juice & Vegetable juice and cocktail & & $\mathrm{NA}^{\S}$ \\
\hline & & $\begin{array}{l}\text { Sugary drinks and } \\
\text { artificially sweetened } \\
\text { beverages }\end{array}$ & $\begin{array}{l}\text { Includes sweetened coffee and tea, } \\
\text { club soda, vitamin and flavoured } \\
\text { waters, artificially sweetened } \\
\text { beverages, juice drinks/cocktails, } \\
\text { juice with sugars added and sodas }\end{array}$ & & $\mathrm{NA}^{\S}$ \\
\hline & & $\begin{array}{l}\text { Sweetened plant-based } \\
\text { beverages }\end{array}$ & $\begin{array}{l}\text { All fortified and non-fortified } \\
\text { sweetened plant-based beverages } \\
\text { that contain protein (e.g., soy) or not } \\
\text { (e.g., almond, cashew, rice, coconut) }\end{array}$ & & $\mathrm{NA}^{\S}$ \\
\hline & & Alcoholic beverages & All beverages with alcohol & & $\mathrm{NA}^{\S}$ \\
\hline \multirow[t]{2}{*}{ Fatty acids ratio } & Numerator & $\begin{array}{l}\text { Total grams of mono- } \\
\text { and polyunsaturated } \\
\text { fats }\end{array}$ & & & \\
\hline & Denominator & $\begin{array}{l}\text { Total grams of } \\
\text { saturated fats }\end{array}$ & & & \\
\hline \multirow[t]{2}{*}{ Saturated fats } & Numerator & $\begin{array}{l}\text { Total calories from } \\
\text { saturated fats }\end{array}$ & & & \\
\hline & Denominator & $\begin{array}{r}\text { Total calories from all } \\
\text { foods and beverages }\end{array}$ & & & \\
\hline \multirow[t]{2}{*}{ Free sugars } & Numerator & $\begin{array}{l}\text { Total calories from free } \\
\text { sugars }\end{array}$ & & & \\
\hline & Denominator & $\begin{array}{l}\text { Total calories from all } \\
\text { foods and beverages }\end{array}$ & & & \\
\hline \multirow[t]{2}{*}{ Sodium } & Numerator & $\begin{array}{l}\text { Total grams from } \\
\text { sodium }\end{array}$ & & & \\
\hline & Denominator & $\begin{array}{l}\text { Total calories from all } \\
\text { foods and beverages }\end{array}$ & & & \\
\hline
\end{tabular}

Note: HEFI, Healthy Eating Food Index; NA, not applicable.

*The denominator for these components is total foods.

'Fortified plant-based cheeses, criteria adapted from (Government of Canada 2017b) and Plant-based beverages, criteria adapted from (Government of Canada 2017a).

${ }^{\ddagger}$ Totals foods exclude fats and oils (e.g., vegetable oils), all beverages without protein as well as herbs, spices and other culinary ingredients (e.g., baking soda).

${ }^{\S}$ Grams are used to calculate the amount of beverages consumed. 


\section{References}

Government of Canada. 2017a. Interim Policy on the Use of Expired Interim Marketing Authorizations Related to Food Fortification (1). Available from https://www.canada.ca/en/health-canada/services/food-nutrition/ legislation-guidelines/policies/interim-policy-on-use-expired-interim-marketingauthorizations-related-food-fortification.html\#a61. [Accessed 7 January 2022.]
Government of Canada. 2017b. Interim Policy on the Use of Expired Interim Marketing Authorizations Related to Food Fortification (4). Available from https://www.canada.ca/en/health-canada/services/food-nutrition/legislationguidelines/policies/interim-policy-on-use-expired-interim-marketingauthorizations-related-food-fortification.html\#a64. [Accessed 7 January 2022.] 